\title{
Importancia del Modelo Turístico Estratégico Pentur 2016 - 2025 como Base en un Contexto de Desarrollo Local
}

Importance of the Strategic Tourist Model Pentur 2016-2025

as Based on a Local Development Context

José Domingo Begazo*

d180045@mixmail.com

Walter Fernández Baca"

wfernandezbaca@pucp.pe

[RECEPCIÓN: AGOSTO 2016 / CONFORMIDAD: OCTUBRE 2016]

\section{RESUMEN}

Este artículo tiene como objetivo presentar reflexiones sobre la importancia y la vigencia del desarrollo turístico en los procesos de desarrollo local, teniendo como base la implementación del PENTUR 2016-2025.

En el Perú, su aplicación, desarrollo e implementación se encuadra en la Ley General de Turismo Ley 29048.

Constituyendo un gran reto para optimizar el desarrollo económico local de las regiones, específicamente las zonas rurales de nuestro país.

Dentro de las reflexiones finales, se destaca que el desarrollo económico local es un proceso que promueve la aceleración y crecimiento de nuestras comunidades en un determinado círculo territorial. Se observa también que estos procesos comprenden cuestiones como la capacidad de decisión, gestión y participación de los actores locales.

Con este énfasis último, el turismo puede promoverse como una actividad económica de innovación y dinamización que contribuya a los procesos de desarrollo local de un territorio; sin embargo, para que pueda gestionarse de una manera adecuada se requiere de una herramienta clave: El Plan Estratégico Turístico 2016 - 2025.

Palabras clave: Modelo turístico estratégico de PENTUR, desarrollo local y actores locales

\section{ABSTRACT}

This article aims to present reflections on the importance and relevance of tourism development in local development processes.

In Peru, its application and implementation is a major challenge to optimize the Local Economic Development of Regions specifically rural areas of our country.

\footnotetext{
* Profesor Principal de la Facultad de Ciencias Administrativas (FCA) de la Universidad Nacional Mayor de San Marcos (UNMSM).

*** Profesor de la Pontificia Universidad Católica del Perú y de la Universidad Nacional Mayor de San Marcos (UNMSM).
} 
In the final reflections stresses that local economic development is a process that promotes the acceleration and growth of our communities in a given territorial circle, it is also noted that these processes include tissues such as decisiveness, management and stakeholder participation local.

With the alter emphasis, tourism can be promoted as an economic activity, innovation and dynamism that contribute to the processes of Local Development of a Territory, however that can be managed in an appropriate manner requires a key tool: The Model Tourism.

Keywords: Model Tourism PENTUR, Local Development, Local Actors.

\section{OBJETIVO DEL ENSAYO}

Difundir y promover que el desarrollo local basado en el turismo es impostergable, dado que muchos de los territorios están protagonizando procesos de recuperación y expansión económica gracias a la evolución que está experimentando el sector turismo.

Difundir diversos documentos y declaraciones internacionales que establecen que el turismo es una actividad que contribuye al desarrollo local y puede constituirse en un instrumento de inclusión y dinamización económica de un territorio. En el caso particular de los países en desarrollo, colabora en la atenuación de la pobreza (ONU, 2012; OMT 1995; OMT, 2003; OMT, 2010).

\section{ARGUMENTACIÓN}

M.A. Acerenza (1997), un especialista en temas de desarrollo económico y local, plantea que el "desarrollo local" es un proceso controlado por los actores locales, donde es particularmente importante la capacidad de gestionar los propios recursos, sabiendo aprovechar estratégicamente los recursos externos, donde resultan fundamentales las capacidades locales (ej. creación, innovación, emprendimiento, gestión, organización, articulación, diálogo, consenso, confianza...), y donde, además, en esos procesos predomina la mirada "abajo-arriba", es decir, tomar el control desde las bases, donde los actores locales asumen el protagonismo de su propio proceso de desarrollo.

Según Hernández Díaz (2000), todo el desarrollo es "local", tanto sea en un país, una región, una provincia, un municipio, etc. La palabra "local" no es sinónimo de pequeño o reducido.

El concepto de "local" adquiere una connotación que pasa a definirse como un ámbito comprendido por un proceso de desarrollo en curso que está pensado o promovido.

Una comunidad se desarrolla cuando convierte en dinámicas sus potencialidades. Sin embargo, para que eso ocurra es preciso reunir varios factores.

Uno de estos factores son las áreas naturales que posee el Perú. Tenemos un potencial tremendo para el ecoturismo, pero esto no será suficiente para que se desarrolle o sea capaz de atraer inversiones en ese sector si las personas del lugar no están capacitadas para trabajar en hotelería, gastronomía, guías de turismo, etc., o si las condiciones de salud o seguridad de la localidad no fueran las adecuadas para recibir a los visitantes; o bien, si no existiera voluntad política por parte del Gobierno local y/o regional, también si el actor principal, como son los miembros de la comunidad, no estuviera interesado en participar y fomentar el turismo como actividad productiva.

Por lo tanto, para volver dinámica una potencialidad es preciso identificar la vocación y descubrir las ventajas de una localidad en relación con otras.

Pero, además, comprender que el desarrollo local no es solo económico, sino que se nutre de diversos factores, vinculados al acceso a condiciones de vida, a la educación, a las dinámicas participativas, entre otros aspectos. 


\section{ACTORES}

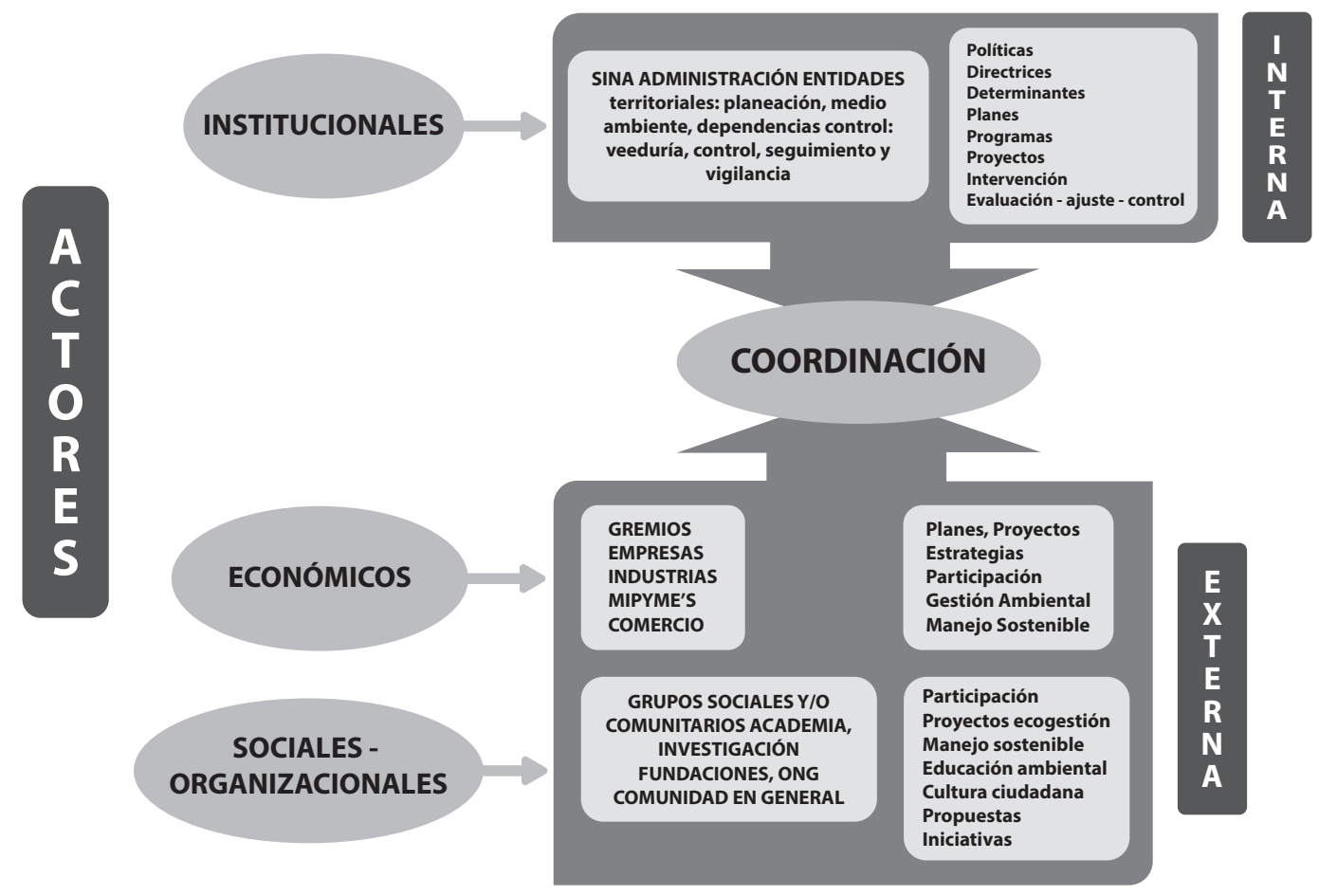

Fuente: http://grupodeinterespentur.blogspot.pe/

Elaboración propia

Ahora bien, el turismo es una actividad económica que propone toda una serie de beneficios sociales, económicos, ambientales y culturales; no obstante, si es deficientemente planificado puede traer ciertos riesgos y, en consecuencia, derivarse en efectos negativos para el desarrollo territorial.

Por lo tanto, es importante tener en cuenta que un destino, sitio o localidad si desea orientar el desarrollo local hacia el turismo, precisa de un método que haga que los esfuerzos invertidos y los recursos utilizados, tanto propios como externos, sean optimizados al máximo y uno de esos métodos es el modelo turístico estratégico de Pentur.

\section{MODELO TURÍSTICO ESTRATÉGICO PENTUR 2016-2025}

Según el Plan Estratégico Nacional de Turismo (PENTUR) 2016 - 2025, la finalidad de un modelo es construir un destino a partir de la calidad e identidad cultural del producto principal, optimizando la comercialización conjunta, el nivel de satisfacción de la demanda y el desarrollo económico-social integral del territorio.
Este nuevo enfoque dinamizará el desarrollo de circuitos y corredores, al dejar de lado los límites departamentales que fueron utilizados para delimitar las zonas turísticas.

Para ello, PENTUR invoca, a través de sus líneas de acción operativas, la creación de productos altamente especializados y diferenciados que permitan el consumo del destino, comercializados conjuntamente desde el propio territorio.

El conocimiento preciso de esta visión compleja y diversa que subyace al producto turístico avanzado y la calidad en servicio como valor y eje organizador común son los instrumentos que permiten concretar un modelo propio y diferente, una realidad única regida por un núcleo de estrategias globales y coherentes.

El desarrollo de esta propuesta de modelo parte de una visión estratégica y consensuada que contempla el amplio espectro de realidades que configuran un modelo territorial, económico, social y turístico.

Sin estos factores integrados en el desarrollo operativo, cualquier propuesta fracasará. 


\section{SISTEMA TURÍSTICO}

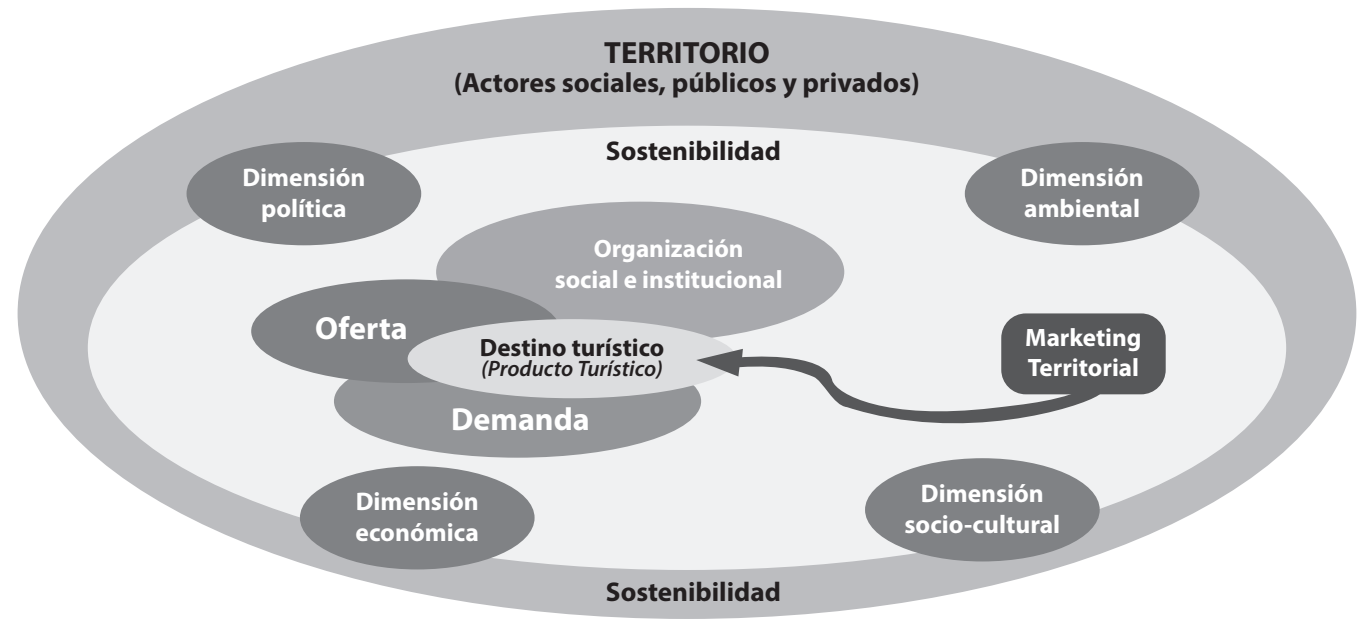

Fuente: PENTUR Ordenamiento Territorio y Turismo

Elaboración Propia

Cuadro 1: Resumen de los contenidos del modelo

\begin{tabular}{|c|c|}
\hline ¿Qué áreas turísticas debemos promocionar? & $\begin{array}{l}\text { Identificar claramente los elementos clave de gestión, promoción } \\
\text { y comercialización. }\end{array}$ \\
\hline ¿En qué situación se encuentra actualmente? & $\begin{array}{l}\text { Definir mediante criterios cuantitativos concretos el desarrollo de } \\
\text { los elementos que componen el destino. }\end{array}$ \\
\hline $\begin{array}{l}\text { ¿Qué impide que alcance un desarrollo turístico } \\
\text { adecuado? }\end{array}$ & $\begin{array}{l}\text { Establecer las amenazas, riesgos y factores condicionantes de } \\
\text { los objetivos propuestos. }\end{array}$ \\
\hline ¿Qué debo y cómo hacerlo? & $\begin{array}{c}\text { Indicar las líneas y programas de actuación para suprimir los } \\
\text { limitantes de los objetivos. }\end{array}$ \\
\hline $\begin{array}{c}\text { ¿Quién debería hacerlo, quién podría ayudarle y } \\
\text { quién podría poner trabas? }\end{array}$ & $\begin{array}{c}\text { Identificar a los actores e interesados de los distintos ámbitos de } \\
\text { gestión. }\end{array}$ \\
\hline $\begin{array}{l}\text { ¿Qué efectos se esperan y cómo saber si se está } \\
\text { haciendo bien? }\end{array}$ & $\begin{array}{c}\text { Definir indicadores de gestión que permitan evaluar la eficacia } \\
\text { respecto a los objetivos. }\end{array}$ \\
\hline $\begin{array}{c}\text { ¿Qué tenemos, qué necesitamos y cuánto cuesta lo } \\
\text { que se pretende hacer? }\end{array}$ & $\begin{array}{l}\text { Establecer los recursos materiales administrativos y presupues- } \\
\text { tarios disponibles y necesarios. }\end{array}$ \\
\hline ¿Cuándo hay que hacerlo? & $\begin{array}{l}\text { Establecer un cronograma de trabajo y un período de vigencia } \\
\text { del plan. }\end{array}$ \\
\hline $\begin{array}{l}\text { ¿Cómo sabremos si estamos haciendo lo previsto } \\
\text { según objetivos marcados? }\end{array}$ & Diseñar un programa de seguimiento de resultados. \\
\hline $\begin{array}{l}\text { ¿Cómo vamos a conseguir implicar a todo aquel } \\
\text { que tenga algo que decir o qué hacer? }\end{array}$ & $\begin{array}{l}\text { Diseñar procesos e instrumentos de participación social e inter- } \\
\text { gubernamental. }\end{array}$ \\
\hline
\end{tabular}

Fuente: Guía Metodológica para la Elaboración de Planes de Gestión de los Lugares Natura 2000 en Navarra. España. PENTUR 


\section{PILARES DEL MODELO TURÍSTICO ESTRATÉGICO PENTUR 2016-2025}

El impacto del PENTUR 2016-2025 está basado en cuatro pilares de desarrollo sectorial:

DIVERSIFICACIÓN Y CONSOLIDACIÓN DE LA OFERTA TURÍSTICA, con la consigna de llegar a tener un destino que no dependa solo de Machu Picchu;

DIVERSIFICACIÓN Y CONSOLIDACIÓN DE MERCADOS, impulsando la promoción en nuevos países emisores de turistas.

FACILITACIÓN TURÍSTICA, teniendo como objetivo la facilitación de las inversiones y el fortalecimiento de la Ventanilla Única de Turismo (VUT) INSTITUCIONALIDAD DEL SECTOR, profesionalización del factor humano, promoviendo la capacitación a nivel nacional.

\section{LOS PILARES DEL MODELO TURÍSTICO PENTUR 2016-2025 Y SU INFLUENCIA PARA EL DESARROLLO DEL TURISMO A NIVEL DE GOBIERNOS LOCALES Y REGIONALES EN EL PERÚ}

Particularmente en el Perú, en la década de 1990, se originó un proceso de transformación caracterizado por la llegada de inversiones de empresas multinacionales.

En consecuencia, los Gobiernos municipales y regionales comenzaron a analizar la diversificación de sus economías y a generar nuevas estrategias de desarrollo ante la necesidad de adaptarse a estas situaciones.

La puesta en práctica de planes estratégicos acompañaron estos procesos, aplicados en distintas escalas territoriales administrativas, $y$, en algunos casos, además focalizados en áreas económicas específicas como, por ejemplo, el turismo (W. Fernández Baca - Separata de Estudios - Escuela Nacional de Gestión Pública 2014).

En esta línea cabe indicar que las reformas instrumentadas durante la mencionada década del noventa en Perú fueron acompañadas por la modificación de la Constitución del año 1993.

Es a partir de esta modificación que se evidenció en el país una tendencia en modelo de gestión desde los municipios y regiones, los cuales pasaron a un rol más activo, con algunas deficiencias propias de la falta de capacitación y experiencias anteriores en materia de gestión pública, aunadas también a casos de corrupción en muchas de sus esferas de Gobierno.
Se observó que los Gobiernos locales y regionales tuvieron intervenciones más directas, mayores responsabilidades, y la adopción de herramientas de gestión que sirvan para mejorar las condiciones socioeconómicas de la población en su conjunto.

En la actividad turística, esa tendencia se hizo evidente favoreciendo el desarrollo de nuevos productos o áreas en municipios que nunca habían considerado el turismo como promotor del desarrollo local.

Dentro de este contexto comienzan a originarse numerosos planes estratégicos que tuvieron lugar especialmente a partir del inicio de 2000. En estos planes, en líneas generales, intervinieron conjuntamente el sector público y el sector privado, contando en muchos casos con la facilitación de equipos técnicos externos, y haciendo efectiva la participación de los actores locales, sobre todo, considerando que la misma podía promover u obstaculizar el desarrollo de un territorio.

La incorporación de los actores locales en los PILARES DEL MODELO TURÍSTICO PENTUR 20162025, en la gestión, ofrece un trabajo de "abajo hacia arriba", y atiende a la realidad, demandas, intereses y necesidades que tiene la misma.

Particularmente, su incorporación en los cuatro pilares busca que los beneficios del desarrollo se mantengan en los residentes locales.

Asimismo, su intervención en estos procesos debe extenderse más allá de la manifestación de su voluntad del desarrollo turístico en la localidad, y llegar también a la formulación de políticas, la implementación y el monitoreo y el seguimiento de los planes.

El integrar a la comunidad local y diversos actores locales en la planificación y la gestión del turismo no es una cuestión sencilla.

En la práctica, son varios los factores que dificultan su incorporación a los procesos de gestión turística, entre ellos: la dificultad de la comunidad ante la comprensión del lenguaje técnico, la heterogeneidad de quienes participan en términos de opiniones e intereses, la baja representatividad de la posición de la comunidad si la participación se circunscribe a grupos muy acotados, o la falta de participación debido la apatía e indiferencia de algunos residentes.

Los diversos planes estratégicos de turismo desarrollados en el Perú en las últimas décadas indi- 
can que la estrategia participativa ha posibilitado la expresión de los distintos actores vinculados al sector. Podemos mejorar esta participación de los actores locales brindando instancias para manifestar las diferentes necesidades y preocupaciones de los actores. Urge también tomar conciencia de quiénes participan sobre las problemáticas a las que se enfrentan y también el conocimiento de la opinión de otros actores de la propia comunidad.

No obstante, estos pilares reconocen que lo participativo se manifiesta solo en un paso de todas las etapas de elaboración del plan y que esta estrategia participativa en los planes turísticos en ocasiones sirve para legitimar una política que ya está definida de antemano.

\section{REFLEXIONES FINALES}

1. A partir de lo desarrollado hasta aquí surgen algunas consideraciones finales sobre el turismo y su vinculación con el desarrollo de un territorio.

2. El desarrollo local es un proceso que promueve el crecimiento de la actividad económica y/o diversificación de la estructura productiva de un territorio.

3. No obstante, estos procesos no solo abarcan aspectos de naturaleza económica, sino que se nutren también de otros factores, como por ejemplo, el protagonismo que asumen los actores en cuanto al poder de decisión y gestión de sus propios recursos, y donde resultan fundamentales las capacidades locales, tales como el conocimiento, la creación, la innovación, el emprendimiento, las formas de organización, articulación, diálogo, consenso y participación, así como los vínculos basados en la confianza.

4. En territorios donde se observan estas características, el turismo puede desarrollarse como, una actividad que permite la dinamización social y económica, y/o ser considerado como un factor de diversificación o reconversión productiva local que contribuya a los procesos de desarrollo local de una comunidad.

5. Pero para que pueda gestionarse de manera ordenada necesita de ciertos instrumentos, como, por ejemplo, la planificación estratégica.
6. En este sentido, los pilares y planes estratégicos constituyen una herramienta que permite orientar el desarrollo local hacia la acción.

7. En la década del 2000 se inician en el Perú nuevos procesos de gestión y administración provinciales y municipales, donde muchas localidades, provincias e inclusive regiones, elaboraron sus respectivos planes estratégicos, y en algunos casos, orientaron esta herramienta específicamente hacia el desarrollo turístico.

8. Acerca de la participación local, si bien se observa que son cada vez más los actores involucrados en los procesos de planificación de un destino turístico, existen estudios que reconocen que esta participación es importante, pero muchas veces es solo figurativa, y solo a los efectos de obtener una validación social de estos procesos.

9. Es posible que algunos de estos planes estratégicos de desarrollo turístico impulsados en el Perú hayan quedado en la plasmación de un documento, o en una implementación parcial.

10. Asimismo, aún no es posible afirmar si han contribuido efectivamente a los procesos de desarrollo local, ya que todavía es necesaria la aplicación de estudios y/o monitoreo de mayor profundidad que permitan reconocer los impactos y alcances que estos han tenido.

11. Más allá de estas apreciaciones, los planes de desarrollo turístico tanto municipales como regionales elaborados en los últimos quince años sirvieron para consensuar ideas y propuestas, promover acciones conjuntas, y sentar precedentes de trabajo en esta línea para mejorar la calidad de la gestión de los destinos turísticos.

\section{BIBLIOGRAFÍA}

ACERENZA, M. A. (1997). "Administración del Turismo. Conceptualización y Organización”. Vol. 1, 4ta. Edición, Ed. Trillas, México.

ANDER-EGG, E. (2007). "Introducción a la Planificación Estratégica”. Ed. Lumen- Hvmanitas, Buenos Aires.

FUNDACIÓN DEMUCA (2009). “Guía práctica para el Agente de Desarrollo Local de Centroa- 
mérica y República Dominicana”, Fundación DEMUCA y CEDeT, San José, Costa Rica.

FERNÁNDEZ BACA SEVILLANO (2014). "Guía práctica para el Fortalecimiento de los actores locales en un contexto de Desarrollo Local", Separata Escuela Nacional de Gestión Pública - Diplomado en Gestión Pública.

HERNÁNDEZ DÍAZ, E. (2009), Planificación Turística. Un Enfoque Metodológico, Ed. Trillas, México.

OIT-CIF - Organización Internacional del Trabajo Centro Internacional de Formación (2004). "Turismo y Desarrollo Local Sostenible: elementos para un debate", Noticias Delnet, Revista electrónica del Programa Delnet de Desarrollo Local, No 34, Turín.

OIT-CIF - Organización Internacional del Trabajo Centro Internacional de Formación (2014a). "Diagnóstico y Planificación Estratégica, ejes centrales de una política local de Turismo Sostenible". En Curso de Turis- mo Sostenible y Desarrollo Local, Unidad Didáctica 5, Programa Delnet de Apoyo al Desarrollo Local, Centro Internacional de Formación, Turín.

OIT-CIF - Organización Internacional del Trabajo - Centro Internacional de Formación (2014b). "Los procesos de desarrollo local y la importancia estratégica del Turismo”. En Curso de Turismo Sostenible y Desarrollo Local, Unidad Didáctica 1, Programa Delnet de Apoyo al Desarrollo Local, Centro Internacional de Formación, Turín.

OMT - Organización Mundial del Turismo (1995). "Carta del Turismo Sostenible". Conferencia Mundial de Turismo Sostenible, Lanzarote.

WALLINGRE, N. (2012). "La Política Turística". En Problemas Turísticos Contemporáneos, Carpeta de Trabajo, Unidad 7, 2da. Edición, Universidad Virtual de Quilmes, Bernal, Argentina. 